Article

\title{
Exchange Rate, Gold Price, and Stock Market Nexus: A Quantile Regression Approach
}

\author{
Rizwan Ali ${ }^{1}$ * , Inayat Ullah Mangla ${ }^{2}$, Ramiz Ur Rehman ${ }^{3}$, Wuzhao Xue ${ }^{4}$, \\ Muhammad Akram Naseem ${ }^{1}$ and Muhammad Ishfaq Ahmad ${ }^{1}$ \\ 1 Lahore Business School, The University of Lahore, Lahore 54100, Pakistan; \\ muhammad.akram@lbs.uol.edu.pk (M.A.N.); muhammad.ishfaq@lbs.uol.edu.pk (M.I.A.) \\ 2 Department of Finance and Commercial Law, Western Michgan University, Kalamazoo, MI 49008, USA; \\ inayat.mangla@wmich.edu \\ 3 School of Management, Xi'an Polytechnic University, Xi'an 710048, China; ramiz_rehman@xpu.edu.cn \\ 4 School of Economics and Management, Xidian University, Xi'an 710126, China; xuewz@xidian.edu.cn \\ * Correspondence: rizwan.ali@lbs.uol.edu.pk
}

Received: 6 June 2020; Accepted: 4 August 2020; Published: 17 August 2020

\begin{abstract}
In this study, we examine an empirical relationship between stock market volatility with the exchange rate and gold prices of an emerging market, "Pakistan", employing daily and monthly data (PSX-100 Index) covering from 2001: Q3 to 2018: Q2. The study explains the average stock returns by applying MGARCH. Further, it investigates that the volatility in the exchange rate (Rs/US $\$$ ) and gold prices remain equally strong in bearish and bullish conditions of the stock market by using a quantile regression approach (2001-2018). Additionally, the sample period is divided into two split samples that cover (2001-2007) and (2008-2018) respectively, based on global financial crises and applied similar analysis. The overall results show the negative impact of the exchange rate and gold price volatility on the stock market performance daily (monthly), supporting the argument that the stock market considers the exchange rate and gold price fluctuations as an adverse indicator and reacts negatively.
\end{abstract}

Keywords: exchange rate; gold price; PSX; quantile regression

\section{Introduction}

In the wake of the financial liberalization of emerging economies, they have received massive capital inflows and financial asset returns, which are essential for portfolio selections, asset pricing, hedging, and risk management. To construct the portfolios, the exchange rate is directly involved; therefore, fluctuation in the exchange rate affects the stock market. The stability of the financial markets enhances their potential to sustain themselves in crises and to face unexpected events. In contrast, an unstable and rapidly fluctuating stock market restricts investor interests and growth-enhancing potential. Market volatility has implications for several macro-economic dimensions (Singhal and Ghosh 2016; Akkoc and Civcir 2019). Therefore, analysts and investors consider this an important factor in investment decisions because it is linked to investment returns, portfolios selection, and risk management strategies. The inter-relationship between the commodity market, foreign exchange, and stock markets raises more concerns because the volatility in one of these markets would have a spillover effect to the other linked markets (Leung et al. 2017; Delgado et al. 2018). Financial integration between markets further increases the intensity of this phenomenon, which includes hedging and risk management perspective (Mun 2007).

Evidence of the inter-relationship between markets is widely reported in developed economies, while researchers shifted their focus towards emerging economics to examine these relationships 
(Masih et al. 2011; Singhal and Ghosh 2016; Bouri et al. 2017; Akkoc and Civcir 2019; Delgado et al. 2018) because of the rapid growth in the stock markets of emerging economies in post-financial liberalization period due to the increased flow of capital which increases the value and volume of these markets.

Despite the positive impact, the vulnerability levels of these markets point toward bad news and global phenomenon, and events affecting the other markets (like a commodity) have increased, therefore, such trend pushes them towards uncertainty and volatility (Ebrahim et al. 2014; Raza et al. 2016). Conventionally, gold is considered as a hedge against inflation, a kind of wealth source, and is, to some extent, considered as a safe investment, especially during the fluctuation period of the stock market. Therefore, economic liaisons increase their gold holdings against inflation with the expectation of a further rise in inflation (Baur and Lucey 2010). During the economic slumps, commodities (gold) create a sense of certainty and opportunity for investors to invest a safe investment (gold) because of its positive correlation with inflation (Bampinas and Panagiotidis 2015). Investment in gold can also be considered as a diversifier of a portfolio due to its low correlation with other assets, which also reduces the overall risk of the portfolio. Even central banks retain gold for diversification to safeguard against economic uncertainty (Chen and Lin 2014). Gold has retained the investment diversification options whereas the volatility of gold prices has a significant negative relation with stock markets. Therefore, it is imperative to understand the behavior of gold market volatility for making portfolio construction or even hedging decisions. Generally, stock markets are influenced by numerous interdependent economic factors, whereas macro-economic variables (gold) and fluctuating prices have a more intense impact on Stock markets (prices). Prior studies (Kanjilal and Ghosh 2014; Shahbaz et al. 2014) analyzed the gold and stock market linkages in linear settings whereas (Sadorsky 2014; Chen and Lin 2014) established that commodity (gold) fluctuations can explain the stock markets.

As an emerging economy, Pakistan is one of the leading consumers of gold, accounting for around $2 \%$ of global consumer demands (CEIC 2020). Pakistan's demand for gold grows up to $16.3 \%$ ( $t$ ) every two years, and the reported gold reserves in Pakistan are 64.60 (t) 3.538 USD 2020: Q1. The gradually growing trend of gold consumption in Pakistan is due to the investment in gold against inflation, and its utilization in the general public as a tradition and in cultural events, including weddings and other religious activities, although gold demand and consumption are directly related to its sensitivity of price, individual income, and investment level. The individual and portfolio investors buy when it is traded as low in regards the local currency, and gain profit when the price shifts to rational-profit margins. Despite the individual investment or portfolio investors, the state of the economy is one of the core drivers of gold demand, which follows the expected inflation and currency weakness trends, which eventually influence the market. Adding to all of the above, the global COVID-19 pandemic is the biggest source of raising the global gold demand, which inched up to $1083.8(t)$ in 2020: Q1. The COVID-19 outbreak, which swept to the globe during the first quarter, was the single prime influencing factor in the gold demand. Due to the scale of the pandemic and its potential economic impact, investors sought safe-haven assets (World Gold Council).

Literature has identified several reasons either in developed or emerging economics that influence the stock market conditions, and its volatilities which include the interest rate, inflation, credit policy, and other macro-level socio-political factors. The fluctuations in gold prices at the international level could have a significant impact on the Pakistan Stock Market (PSX). For instance, in Pakistan, investors shifted their investment trends toward gold bars instead of stock market after losing hope to gain satisfactory returns. This study provides some new evidence from PSX by applying the Multivariate GARCH and quantile regression techniques to measure the relationship between exchange rate, commodity (gold), and PSX. The sample of this study covers the period from 2001: Q3 to 2018: Q2. In comparison with the prior studies, this study covers a long set of data that allows us to provide insights from the pre-global financial crises and the post-global financial crises. In post-global financial crises, the high fluctuations in exchange rate, and gold prices, which significantly impact the stock market, include the gold price peak in 2011 and the decline later. Raza et al. (2016) considered gold as an essential factor in decision making regarding investment; the lag price of gold can also 
be a predictor of future, (Kumar 2017). Therefore, the implications of time-varying volatility of the relationship between the exchange rate, gold price, and stock market are the key to diversification for making a diverse portfolio, hedging, and to manage risk. Few studies have measured the impact of change in rate and commodity (gold) prices on the PSX. Therefore, this study enhances this discussion pattern and focusing primarily on the pre-crisis and post-crisis era. Consequently, this study aims to examine the relationship and correlation among the exchange rate, gold price, and the stock market returns. The study uses Multivariate-GARCH and quantile regression to explore this relationship, which confirms the empirical results and provides consistent and more rigorous results (Akkoc and Civcir 2019).

The rest of the paper is organized as follows: Section 2 reviews the related literature; Section 3 describes the research design includes sample and applied methodology. Section 4 describes the results and interpretations, and lastly, Section 5 concludes the study.

\section{Literature Review}

Literature suggests that there are multiple channels regarding the relationship with gold, including; inflation (Aye et al. 2017), fluctuations in exchange rates (Le and Chang 2016), portfolio allocations (Reboredo 2013), and the flow-oriented approach which hypothesizes that the change in exchange rate affects firm earnings and stock prices (Dornbusch and Fischer 1980). Researchers have examined the link between the gold price and the return form stock markets, and tried to settle this debate; either gold is a safe investment against the stock market or vice-versa, and the risk-return trait is compared. The few of them that documented that gold can hedge against inflations includes: Baur and Lucey (2010) for developed States; Baur and McDermott (2010) for both developing and developed states; and Sreekanth and Veni (2014) for an emerging State India. Conversely, Beckmann et al. (2015) indicated that the ability of gold hedging against inflation could vary from state to state. Further, the past gold prices are another predictor of the stock market returns (Mensi et al. 2013; Kumar 2017) and hold interaction with each other (Arouri et al. 2015; Raza et al. 2016). Hence, the relationship between gold markets, exchange rates, and stock markets have widely been studied in the literature. However, the same interdependence is less reported and examined in developing and emerging economies, for instance, (Masih et al. 2011; Jain and Biswal 2016; Bouri et al. 2017).

Mun (2007) has found a strong correlation between the exchange rate fluctuations and volatility of the local stock market. In literature, researchers empirically test the relationship of the exchange rate in both developed and emerging countries using various estimation techniques. For example: Walid et al. (2011) applied Markov-switching EGARCH to derive linkage between exchange rate and stock market returns in three Asian countries (Hong Kong, Singapore, and Malaysia) and one North American country (Mexico), considering both crisis and regular regimes. The results revealed that the relationship between foreign exchange and the stock market is regime-dependent, and stock volatility was influenced through events. Rjoub et al. (2017) investigated the particular relationship between bank stock returns, considering their importance to represent the financial sectors and micro-macro factors. Generally, this study reported that both elements are related to stock prices, primarily asset quality, interest rate, and it concluded that bank stock returns negatively react to economic crises. Delgado et al. (2018), documented a study on Mexico and found that the exchange rate increase results in the negative performance of the stock market index and vice versa. Therefore, the Mexican stock market considers an increase in the exchange rate as a contrary indicator, and this effect spills over into the stock market as well. Leung et al. (2017) found the paired evidence between the exchange rate and capitalization of the stock market in Asia and Europe.

Akkoc and Civcir (2019) examined the relationship between commodities and stock market returns in the BIST 100 Turkey stock market, considering after global financial crises-applied DCC-GARCH and found the highest correlation among studies during the years 2011 and 2012, additionally finding high volatility with gold. Baur and McDermott (2010) investigated the same relationship and concluded that gold is a safe source of investment, especially during economic downturn situations, and provides 
confidence to investors. In contrast, Baur and Lucey (2010) found gold as a safe investment due to a negative correlation with the stock market. Iqbal (2017) stated that gold acts as a safe investment against the exchange rate risk in India and Pakistan's emerging economies. Still, its hedging potential with other asset classes like the risk of stock market fluctuation needs further investigation. According to Baur (2012), the gold price volatility exerts a negative impact on the financial markets. It showed the importance of studying the fluctuations in the prices of gold and its relation to investment decisions (Ewing and Malik 2016).

Despite other variables, which affect the stock market price index, the gold price has the most impact on the stock market's S\&P price index (Gokmenoglu and Fazlollahi 2015). Raza et al. (2016) concluded that gold prices positively influence the stock prices of large emerging economies (BRICS), but small emerging economies' stock markets have a negative relation with gold prices. Jain and Biswal (2016) found that the fall in the prices of gold and oil resulted in the depreciation of the Indian rupee and the downward movement of the benchmark index of the stock market. It provides another exciting phenomenon; that gold prices impact the exchange rate, which further affects stock returns. Despite the establishment of the relationship between these markets, the link between volatility spillovers from the exchange rate to the stock market is limited. Wong (2019) studied the Malaysian context and found a weak relationship between the foreign exchange market and the stock market. There is literature that exists and explores the nexus of the exchange rate and gold price volatility with stock markets; however, the consensus remains indispensable and demands further exploration (Caporale et al. 2014; Tule et al. 2018).

Therefore, this study examined the volatility of the exchange rate and gold prices with the stock market of Pakistan. As an emerging economy, Pakistan has faced-and faces-many economic challenges, including high interest, export decline, and trade deficit. During the crisis period, the trade deficit widened further, which worsened the economic conditions by currency depreciation. Interest rates increased to control inflation, resulting in a decrease in the profits due to high financing costs, which affected investor's confidence. Hence, the flight of capital further hampered the economy. Therefore, this study empirically provides new evidence using M-GARCH and quantile regression, contributing to the empirical literature, and offering new insights for further research and policy development.

\section{Research Design}

\subsection{Sample}

The primary source of data employed in this study is taken from the Pakistan Stock Exchange (PSX) and State Bank of Pakistan (SBP). The KSE 100 index data is obtained from the official web of PSX while the exchange rate (USD/PKR) and gold price (USD/troy ounce) data are collected from the SBP and business recorder database. After this, the returns of these variables are used by taking the log difference of two consecutive periods and the respective observation of specific off-days is dropped to synchronize data. Figure 1, presents the visual image that shows the fluctuations of the studied variables over time. Pakistan's stock market has its significance in the region. It is ranked in the best four performing markets in Asia, with an annual return of $46 \%$ in 2016, and it has been upgraded to MSCI's emerging market status. The key to employing the KSE100 index is to have a benchmark to compare the stock market performance over time. Considering the importance of the Pakistan stock market in the emerging economies context, the study examines how the exchange rate and gold price volatility affect the stock market.

For this instance, daily and monthly data from 2001: Q3 to 2018: Q2 are used. The study period is essential due to its various political shifts, economic ups and downs, and a phenomenal structural change in stock markets that replaced the separate and three individual stock exchanges to a single and centralized entity "PSX" in 2016. To avoid the disturbance of the U.S. financial crisis in December 2007, we separated the dataset into two periods. According to the U.S. "National Bureau of Economic Research", the U.S. global recession started in the last quarter of 2007. For instance, this study split 
the data into two sub-groups that consider the pre-crisis period from 2001: Q2 to 2007: Q4 and the post-crisis period from 2008: Q1 to 2018: Q2 to separately examine the behavior of the stock market and the influence of the exchange rate and gold price volatility.
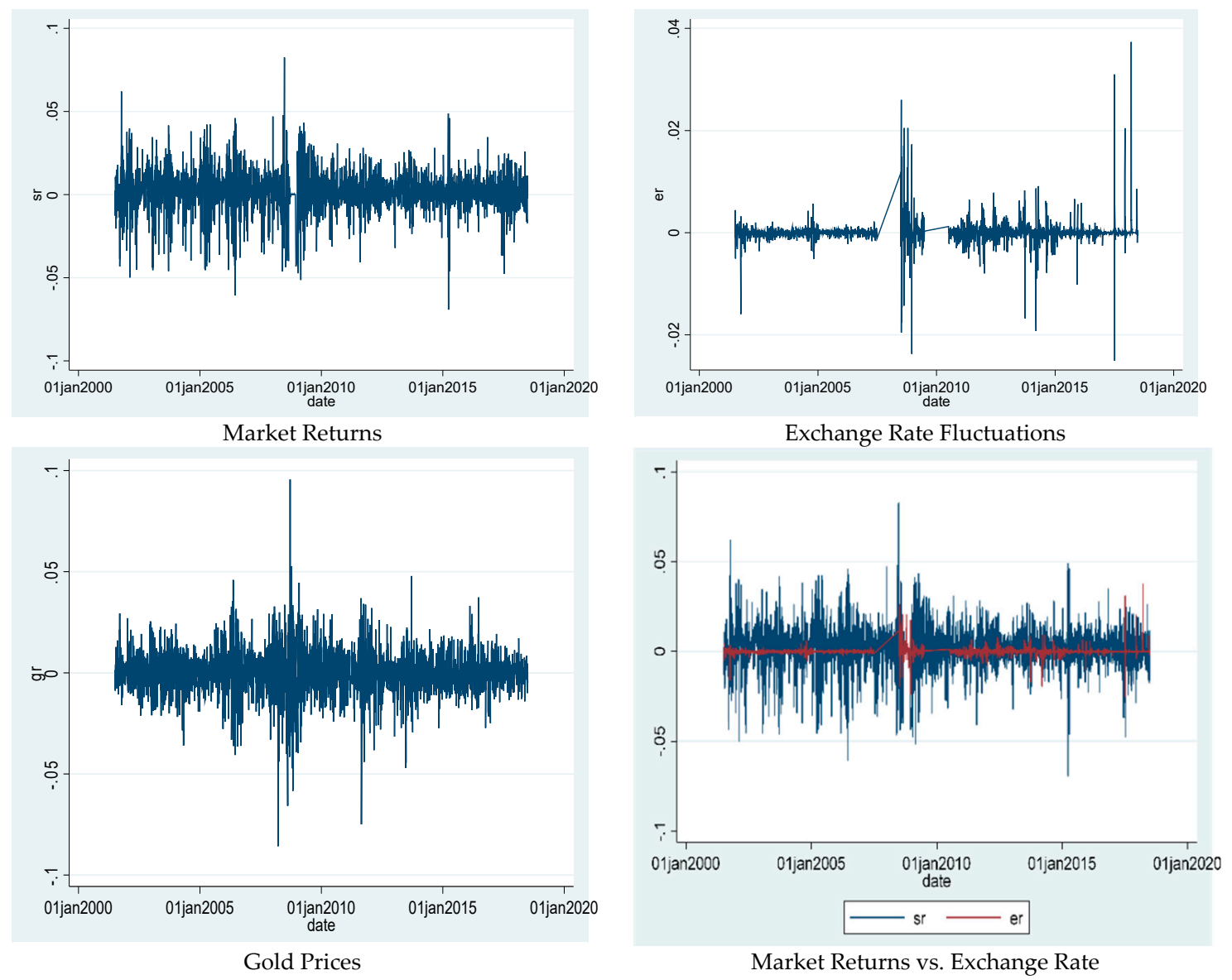

Figure 1. Market returns, exchange rate, gold price, and market return with exchange rate.

\subsection{Empirical Models}

The study objective to examine the relationship between the exchange rate, gold prices, and the stock market nexus. For instance, this study first performed unit root tests to avoid the problem of spurious regression. The Augmented Dickey-Fuller (Dickey and Fuller 1979, 1981; Phillips and Perron 1988; Ng and Perron 2001) tests are adopted. The methodology of these tests shown below:

$$
y_{t}=\phi_{1} y_{t-1}+\varepsilon_{t}
$$

where $t=1, \ldots, \mathrm{T}, \phi_{1}$ is the auto-regression parameter, $\varepsilon_{t}$ is the non-systematic component of the model. The null hypothesis is $\mathrm{H}_{0}: \phi_{1}$, i.e., the process contains a unit root and therefore it is non-stationary, and is denoted as $\mathrm{I}(1)$, alternative hypothesis is $\mathrm{H}_{1}:\left|\phi_{1}\right|<1$, i.e., the process does not contain a unit root and is stationary, $\mathrm{I}(0)$. To calculate the test statistic for DF test, we use an equation that we get if $y_{t-1}$ is subtracted from both sides of the Equation (1):

$$
\Delta y_{t}=\beta y_{t-1}+\varepsilon_{t}
$$

where $\beta=\phi_{1}-1$. The test statistic is defined as:

$$
t_{D F}=\frac{\hat{\phi}_{1}-1}{s_{\hat{\phi} 1}}
$$


where $\hat{\phi}_{1}$, is a least square estimate of $\phi_{1}$ and $s_{\hat{\phi} 1}$ is its standard error estimate.

Model (1) can be expanded by a constant or a linear trend:

$$
\begin{gathered}
y_{t}=\beta_{0}+\phi_{1} y_{t-1}+\varepsilon_{t} \\
y_{t}=\beta_{0}+\beta_{1} t+\phi_{1} y_{t-1}+\varepsilon_{t}
\end{gathered}
$$

In the case when a non-systematic component in DF models is auto-correlated, Model (1) is then transformed as:

$$
y_{t}=\phi_{1} y_{t-1}+\sum_{i=1}^{p-1} \gamma_{i} \Delta y_{t-1}+\varepsilon_{t}
$$

However, the following equation is used to test ADF:

$$
y_{t}=\left(\phi_{1}-1\right) y_{t-1}+\sum_{i=1}^{p-1} \gamma_{i} \Delta y_{t-1}+\varepsilon_{t}
$$

The choice of lags selection $p$ suggested by Schwert (2002) that the maximum lag $p_{\max }=$ $12(T / 100)^{1 / 4}$, because if, $p$ is too low, the test will be affected by autocorrelation and if $p$ is too large, the power test will be lower. Therefore, model (6) further explained by a constant, or linear trend as well.

$$
y_{t}=d_{t}+\phi_{1} y_{t-1}+\sum_{i=1}^{p-1} \gamma_{i} \Delta y_{t-1}+\varepsilon_{t}
$$

where $d_{t}=\sum_{i=0}^{p} \beta_{i} t^{i}$, for $p=0,1$, contains deterministic parts of the models.

In the unit root testing of time series generated by the process with auto-correlated and heteroscedastic non-systematic component, there is often a problem of selection of lag $p$ in the regression mode that deals with the Phillips and Perron test.

This test is also based on the models (1), (4) and (5) with the difference that the linear trend in the last model is replaced by a centered time variable. This test does not use the differentiated equations for the test statistics calculation, but it derives it directly from Equations (1), (4) and (5).

The test statistics $Z$ for model with a constant are written as follows (Pesaran 2015):

$$
\begin{gathered}
Z_{\phi}=T\left(\hat{\phi}_{T}-1\right)-\frac{1}{2} \frac{T^{2} s_{\hat{\phi}}^{2}}{s_{T}^{2}}\left(s_{L T}^{2}-s_{T}^{2}\right) \\
Z_{T}=\left(\frac{s_{T}}{s_{L T}}\right) t_{D F}-\frac{1}{2}\left(s_{L T}^{2}-s_{T}^{2}\right) \frac{1}{s_{L T}} \frac{T s_{\hat{\phi}}}{s_{T}}
\end{gathered}
$$

where:

$$
t_{D F}=\frac{\hat{\phi}_{T}-1}{s_{\hat{\phi}}}, s_{T}^{2}=\frac{1}{T} \sum_{t=1}^{T} \hat{\varepsilon}_{t}^{2}, s_{L T}^{2}=s_{T}^{2}+2 \sum_{j=1}^{q}\left(1-\frac{j}{q+1}\right) \hat{\gamma}_{j, T}, \text { and } \hat{\gamma}_{j, T}=\frac{1}{T} \sum_{t=j+1}^{T} \hat{\varepsilon}_{t} \hat{\varepsilon}_{t-j}
$$

$t_{D F}$ is the test statistics of DF test, $s_{T}^{2}$ is the OLS estimator of the non-systematic component variance, $\hat{\gamma}_{j, T}$ is the maximum likelihood estimator and $q$ is a number of lag of covariates.

If $\varepsilon_{t}$ is not auto-correlated, then $\hat{\gamma}_{j, T}=0$, for $j>0$, and $s_{L T}^{2}=s_{T}^{2}$, the limiting distribution of the test statistics $t$ is therefore not dependent on autoregressive parameters of $\varepsilon_{t}$ process. The test statistics $\mathrm{Z}$ are consequently reduced to $t_{D F}$ test statistics. 
Based on Equation (8), the test uses test statistics Z from the PP test that had been modified by (Ng and Perron 2001):

$$
\begin{gathered}
\overline{M Z}_{\phi}=\left(T^{-1} y_{t}^{*}-s_{A R}^{2}\right)\left(2 T^{-2} \sum_{t=1}^{T} y_{t-1}^{*}\right)^{-1} \\
\overline{M S B}=\left(T^{-2} \sum_{t=1}^{T} \frac{y_{t-1}^{*}}{s_{A R}^{2}}\right)^{1 / 2} \\
\overline{M Z}_{T}=\overline{M Z}_{\phi} \cdot \overline{M S B}
\end{gathered}
$$

where $s_{A R}^{2}=\left(\sum_{t=p+1}^{T} \varepsilon_{t}^{2}\right)\left[(T-k)\left(1-\sum_{i=1}^{p} \hat{\beta}_{i}\right)^{2}\right]^{-1}$, and marked as $M$ tests.

In addition, Multivariate GARCH applied to measure the relationship between exchange rate, gold price, and stock market which includes ARCH L (1) and GARCH L (1). To model a time series using an $\mathrm{ARCH}$ process, let $\varepsilon_{t}$ denote the error terms (return residuals, with respect to a mean process), i.e., the series terms. These $\varepsilon_{t}$ are split into a stochastic piece $z_{t}$ and a time-dependent standard deviation $\sigma_{t}$ characterization the typical size of the terms so that:

$$
\varepsilon_{t}=\sigma_{t} z_{t}
$$

The random variable $z_{t}$ is a strong white noise process. The series $\sigma_{t}^{2}$ is modeled by:

$$
\sigma_{t}^{2}=\alpha_{0}+\alpha_{1} \varepsilon_{t-1}^{2}+\ldots+\alpha_{q} \varepsilon_{t-q}^{2}=\alpha_{0}+\sum_{i=1}^{q} \alpha_{i} \varepsilon_{t-i}^{2}
$$

where $\alpha_{0}>0$ and $\alpha_{i} \geq 0, i>0$.

In $\operatorname{GARCH}(p, q)$ model (where $p$ is the order of the GARCH terms $\sigma^{2}$ and $q$ is the order of the $\mathrm{ARCH}$ terms $\varepsilon^{2}$ ), following the notation of the original paper, is given by:

$$
\begin{gathered}
y_{t}=x^{\prime}{ }_{t} b+\varepsilon_{t} \\
\varepsilon_{t} \mid \psi_{t-1} \sim N\left(0, \sigma_{t}^{2}\right) \\
\sigma_{t}^{2}=\omega+\alpha_{1} \varepsilon_{t-1}^{2}+\ldots+\alpha_{q} \varepsilon_{t-q}^{2}+\beta_{1} \sigma_{t-1}^{2}+\ldots+\beta_{p} \sigma_{t-p}^{2}=\omega+\sum_{i=1}^{q} \alpha_{i} \varepsilon_{t-i}^{2}+\sum_{i=1}^{p} \beta_{i} \sigma_{t-i}^{2}
\end{gathered}
$$

Further, we applied the ordinary least square (OLS) to estimate the linear regression trend and quantile regression, which allows the estimation of various quantile functions in a conditional distribution. By applying the quantile regression, each quantile regression characterizes a particular point that further explained the results into multiple patches and strengthens the empirical results. As the objective of this study is to emphasize the various relationship between exchange rate, gold price, and the stock market, therefore quantile regression provides more details of the studied relationships. The model is illustrated as follows:

Suppose there is a linear specification for conditional quantiles of $E$,

$$
E_{t}=X_{t} \beta+u_{t}
$$

where $E_{t}$ is the stock market; $X_{t}$ is $k \times 1$ regressors, which is constant, and the exchange rate, and gold price used in this study respectively; $\beta$ is the coefficients the model wants to estimate, and the goal of the quantile regression model is to estimate $\beta$ for different conditional quantile functions; and $u_{t}$ is error term. 
Further, the conditional mean of $E$ is $\mu(X)=X^{\prime} \beta$, the approach of ordinary least squares is to estimate the mean,

$$
\min _{\mu \in R} \sum_{t=1}^{n}\left(E_{t}-\mu\right)^{2}
$$

That is:

$$
\min _{\beta \in R} \sum_{t=1}^{n}\left(E_{t}-X^{\prime} \beta_{t}\right)^{2}
$$

Solving above equation will provide the estimation of median (0.5th quantile) function. For the other quantiles, we let $\tau$ stand for quantile variable. The conditional quantile function can be written as:

$$
Q_{E}(\tau \mid X)=X^{\prime} \beta(\tau)
$$

To obtain estimation of the conditional quantile functions, we need to solve

$$
\min _{\beta \in R^{p}} \sum_{t=1}^{n} \rho_{\tau}\left(E_{t}-X^{\prime} \beta_{t}\right)
$$

To minimize the following equation:

$$
\min _{\hat{\beta}}\left[\tau \sum_{E_{t} \geq \hat{\beta} X_{t}}\left|E_{t}-\hat{\beta} X_{t}\right|+(1-\tau) \sum_{E_{t}<\hat{\beta} X_{t}}\left|E_{t}-\hat{\beta} X_{t}\right|\right]
$$

where $X^{\prime}{ }_{t} \hat{\beta}_{\tau}$ is an approximation to the $\tau$ th conditional quantile of $E$, when $\tau$ is close to zero (one), $X^{\prime}{ }_{t} \hat{\beta}_{\tau}$ characterizes the behavior of $E$ (Tsai 2012).

\section{Descriptive Results}

The descriptive statistics are shown in Table 1. It covers the sample period from 2001-2018. The average daily market return during the study period is $0.14 \%$, with $1.23 \%$ volatility. It shows high uncertainty in market returns. Further, the average daily exchange rate return is fairly smaller, $0.002 \%$ to market returns with less volatility of $0.22 \%$, while the average daily gold return shows a negative value of $-0.004 \%$ with $1.08 \%$ volatility, which is quite high as compared to the return value. The first split sample (2001-2007) presents the average daily market return during the study period, $0.18 \%$, with $1.48 \%$ volatility, which is slightly better than the full sample results. However, the average daily exchange rate returns show the negative value $-0.006 \%$ with low volatility of $0.09 \%$, which is quite different from the full sample results. Moreover, the average daily gold return is $0.02 \%$, which shows impressive results as compared to the full sample results with $0.99 \%$ volatility. The second split sample (2008-2018) shows the average daily market return of the study period is $0.11 \%$, which is similar to the full sample results with the marginally low volatility of $1.09 \%$. However, the average daily exchange rate returns show a positive value of $0.008 \%$ with $0.27 \%$ volatility, which is quite different from the first split sample and full sample results. Moreover, the average daily gold return shows again the negative value of $-0.02 \%$, which is similar to the full sample results with $1.12 \%$ volatility.

Table 2, shows the correlation matrix of the study variables. The exchange rate return and the gold return have a negative correlation with market returns in the full sample. While, the same relation is observed positive in the first split sample, whereas it shows a negative relationship in the second split sample. Further, the market return also observes a negative correlation with the exchange rate that confirms the argument that the negative relation between exchange rate and market returns is more evident when the exchange rates follow high (low), extreme trends (Tsai 2012). Table 3, presents the Augmented Dicky-Fuller (ADF), Phillips-Perron (PP), and Ng-Perron test results with trends that 
indicate the exchange rate, gold price, and market returns are stationary at this level with a $1 \%$ level of significance.

Table 1. Descriptive statistics.

\begin{tabular}{lccccccc}
\hline \multicolumn{1}{c}{ Variable } & Obs & Mean & SD & Min & Max & Skew & Kurt \\
\hline \multicolumn{7}{c}{ Full Sample 2001-2018 } \\
\hline Market Return & 3228 & 0.00135 & 0.01238 & -0.06684 & 0.08604 & -0.27351 & 6.60031 \\
Exchange Rate & 3228 & 0.00002 & 0.00227 & -0.02504 & 0.03734 & 2.51386 & 76.45716 \\
Gold Price & 3228 & -0.00004 & 0.01084 & -0.08571 & 0.09554 & -0.22967 & 9.10732 \\
\hline \multicolumn{7}{c}{ Split Sample 2001-2007 } \\
\hline Market Return & 1040 & 0.00188 & 0.01488 & -0.05882 & 0.06403 & -0.39434 & 4.68177 \\
Exchange Rate & 1040 & -0.00006 & 0.00097 & -0.01592 & 0.00567 & -4.60093 & 75.95287 \\
$\quad$ Gold Price & 1040 & 0.00028 & 0.00999 & -0.04059 & 0.04591 & -0.09609 & 4.96092 \\
\hline & \multicolumn{7}{c}{ Split Sample 2008-2018 } \\
\hline Market Return & 2188 & 0.00110 & 0.010991 & -0.06684 & 0.08604 & -0.169474 & 8.27509 \\
Exchange Rate & 2188 & 0.00008 & 0.002760 & -0.02504 & 0.03734 & 2.29305 & 55.05006 \\
Gold Price & 2188 & -0.00019 & 0.011227 & -0.08571 & 0.09554 & -0.264639 & 10.21202 \\
\hline
\end{tabular}

Table 2. Correlation matrix-full sample.

\begin{tabular}{cccccccccc}
\hline & \multicolumn{3}{c}{ Full Sample 2001-2018 } & \multicolumn{3}{c}{ Split Sample 2001-2007 } & \multicolumn{3}{c}{ Split Sample 2008-2018 } \\
\hline Variables & MR & ER & GP & MR & ER & GP & MR & ER & GP \\
\hline MR & 1.000 & & & 1.000 & & & 1.000 & & \\
ER & -0.065 & 1.000 & & -0.026 & 1.000 & & $-0.072 *$ & 1.000 & \\
GP & -0.001 & -0.033 & 1.000 & 0.034 & 0.011 & 1.000 & -0.017 & $-0.046^{*}$ & 1.000 \\
\hline
\end{tabular}

Notes: MR indicates Market returns, ER indicates Exchange rate, and GP indicates Gold price respectively. *, shows the level of significance at $5 \%$.

Table 3. Unit root test results.

\begin{tabular}{cccccccccc}
\hline & \multicolumn{3}{c}{ Full Sample 2001-2018 } & \multicolumn{3}{c}{ Split Sample 2001-2007 } & \multicolumn{3}{c}{ Split Sample 2008-2018 } \\
\hline Variables & ADF & PP & NGP & ADF & PP & NGP & ADF & PP & NGP \\
\hline & Level & Level & Level & Level & Level & Level & Level & Level & Level \\
\hline MR & $-12.442^{* * *}$ & $-12.385^{* * *}$ & $-12.981^{* * *}$ & $-10.124^{* * *}$ & $-9.925^{* * *}$ & $-9.435^{* * *}$ & $-11.214^{* * *}$ & $-12.022^{* * *}$ & $-9.930^{* * *}$ \\
ER & $-11.413^{* * *}$ & $-11.504^{* * *}$ & $-14.973^{* * *}$ & $-10.265^{* * *}$ & $-10.105^{* * *}$ & $-12.980^{* * *}$ & $-10.853^{* * *}$ & $-11.045^{* * *}$ & $-14.937^{* * *}$ \\
GP & $-14.502^{* * *}$ & $-14.536^{* * *}$ & $-10.191^{* * *}$ & $-11.206^{* * *}$ & $-11.524^{* * *}$ & $-9.736^{* * *}$ & $-12.242^{* * *}$ & $-12.359^{* * *}$ & $-10.194^{* * *}$ \\
\hline
\end{tabular}

Notes: ADF indicates Augmented Dicky-Fuller; PP indicates Phillips-Perron, NGP indicates Ng-Perron, MR indicates Market returns, ER indicates Exchange rate, and GP indicates Gold price respectively, significant at a "level" as the significance level of $1 \%$ ***.

\subsection{Multivariate-GARCH}

Table 4, presents the MGARCH results of market return with the exchange rate and gold price on a daily and monthly basis. Exchange rate fluctuations show a significantly negative relationship with market return in the daily observation, while gold price shows an insignificant positive relationship with market returns. On the other hand, the ARCH and GARCH results at lag (1) are significantly positive at a $1 \%$ level of significance in both cases, which confirms that the market return depends on their previous trading day returns and variance except the unexpected incident. However, the exchange rate and gold price results show an insignificant but negative relation in monthly observations. On the other hand, the ARCH and GARCH results at lag (1) are quite similar to daily observations results, which confirms the market return trends based on mean and variance values except in one case, which is insignificant but illustrates the positive relation. 
Table 4. MGARCH results.

\begin{tabular}{ccccc}
\hline & Daily & \multicolumn{2}{c}{ Monthly } \\
\hline Variable & \multicolumn{2}{c}{ Market Return } & \multicolumn{2}{c}{ Market Return } \\
\hline \multirow{2}{*}{ Exchange Rate } & $-0.627^{* *}$ & & -1.06 \\
& $(-3.24)$ & $(-1.20)$ & -0.05 \\
Gold Price & \multicolumn{3}{c}{0.0104} & $(-0.61)$ \\
& $(0.58)$ & $0.02^{* * *}$ \\
Constant & $0.00162^{* * *}$ & $0.00155^{* * *}$ & $0.02^{* * *}$ & $(7.03)$ \\
& $(9.73)$ & $(9.70)$ & $(6.69)$ & 0.01 \\
ARCH L1 & $0.245^{* * *}$ & $0.242^{* * *}$ & $0.030^{*}$ & $(0.73)$ \\
& $(7.77)$ & $(8.21)$ & $(1.67)$ & $0.98^{* * *}$ \\
GARCH L1 & $0.831^{* * *}$ & $0.818^{* * *}$ & $-1.02^{* * *}$ & $(34.31)$ \\
& $(7.19)$ & $(7.46)$ & $(-131.38)$ & 0.0000 \\
Constant & -0.0000 & -0.0000 & $0.004 * * *$ & $(-0.14)$ \\
Obs & $(-1.06)$ & $(-0.90)$ & $(11.33)$ & 204 \\
AIC & 3228 & 3228 & 204 & -680.50 \\
BIC & $-18,109.3$ & $-20,212.6$ & -682.04 & -663.91 \\
\hline
\end{tabular}

Notes: $z$ statistics in parentheses ${ }^{*} p<0.05,{ }^{* *} p<0.01,{ }^{* * *} p<0.001$.

\subsection{Empirical Results}

To estimate the effect of exchange rate and gold price volatility on the stock market, an OLS and Quantile regression P25th-P90th analysis is applied. The results of the full sample show that the exchange rate has a significant impact on market return. The daily and monthly market returns are used for the analysis along with the exchange rate and gold price for the full sample and split-sample period. Table 5, shows the results of the market return with an exchange rate. The results of OLS regression show that the fluctuations in the exchange rate have a negative and significant impact on market return, and the quantile regression also depicts that the exchange rate has a negative and significant effect on market return except for the first quartile of the sampled period. In the next phase of the analysis, the total sample period is split into two sub-sample periods considering the U.S. financial crises. The first split sample covers the period from 2001: Q3 to 2007: Q4, and the second split sample covers the period from 2008: Q1 to 2018: Q2.

After splitting the full sample, the same relationship is applied to examine the effect of the exchange rate on market return. The results are quite different from the overall sample results. The first split sample results show an insignificant but negative relation of exchange rate on market return, while the second split sample results show that the exchange rate has a negative and significant impact on market return, which is in line with the full sample results. The direction and significance of before and after split sample results indicate that the fluctuations of the exchange rate have a more significant effect on market return after the financial crises. In contrast, the OLS regression results of the market return with gold price show that the fluctuations in the gold price have an insignificant but positive impact on market return. On the other hand, the quantile regression shows the more realistic results; that the gold price has an insignificant negative impact on market return for the first three quarters, and the last quarter shows insignificant positive results of the sampled period. In the next phase of the analysis, after splitting the full sample, the same relationship is applied to examine the effect of the gold price on market return. The results are quite similar to the overall sample results; however, the magnitudes are different. The first split sample results show an insignificant but negative relation of exchange rate on market return. The second split sample results show that the gold price has an insignificant negative impact on market return for both OLS and all quarters of quantile regression except P25th. The direction and significance of before and after split sample results indicate that the fluctuations of the gold price have a more negative effect on the market return after the financial crises. 
Table 5. Regression results (Daily)

\begin{tabular}{|c|c|c|c|c|c|c|c|c|c|c|c|c|c|c|c|}
\hline \multicolumn{16}{|c|}{ Market Return with Exchange Rate } \\
\hline & \multicolumn{5}{|c|}{ Full Sample 2001-2018 } & \multicolumn{5}{|c|}{ Split Sample 2001-2007 } & \multicolumn{5}{|c|}{ Split Sample 2008-2018 } \\
\hline & OLS & P25th & P50th & P75th & P90th & OLS & P25th & P50th & P75th & P90th & OLS & P25th & P50th & P75th & P90th \\
\hline $\begin{array}{l}\text { Exchange } \\
\text { Rate }\end{array}$ & $\begin{array}{c}-0.684^{* *} \\
(-3.18)\end{array}$ & $\begin{array}{l}0.732 \text { * } \\
(-2.55)\end{array}$ & $\begin{array}{c}-0.654^{* *} \\
(-3.10)\end{array}$ & $\begin{array}{c}-0.826^{* *} \\
(-2.71)\end{array}$ & $\begin{array}{c}-1.098^{*} \\
(-2.18)\end{array}$ & $\begin{array}{l}-0.378 \\
(-0.73)\end{array}$ & $\begin{array}{l}-0.799 \\
(-1.04)\end{array}$ & $\begin{array}{l}-0.431 \\
(-0.68)\end{array}$ & $\begin{array}{l}-0.365 \\
(-0.51)\end{array}$ & $\begin{array}{l}-0.698 \\
(-0.71)\end{array}$ & $\begin{array}{c}-0.741^{* * *} \\
(-3.32)\end{array}$ & $\begin{array}{c}-0.642 * \\
(-2.14)\end{array}$ & $\begin{array}{c}-0.610 \text { ** } \\
(-2.97)\end{array}$ & $\begin{array}{c}-0.926^{* *} \\
(-2.77)\end{array}$ & $\begin{array}{c}-0.777^{* *} \\
(-1.43)\end{array}$ \\
\hline Constant & $\begin{array}{c}0.001 * * * \\
(8.07)\end{array}$ & $\begin{array}{c}-0.004 \text { *** } \\
(-16.63)\end{array}$ & $\begin{array}{c}0.001 * * * \\
(7.09)\end{array}$ & $\begin{array}{c}0.007 * * * \\
(29.11)\end{array}$ & $\begin{array}{c}0.014^{* * * *} \\
(34.08)\end{array}$ & $\begin{array}{c}0.002 * * * \\
(5.90)\end{array}$ & $\begin{array}{c}-0.004^{* * *} \\
(-8.53)\end{array}$ & $\begin{array}{c}0.0024^{* * *} \\
(5.85)\end{array}$ & $\begin{array}{c}0.009 * * * \\
(20.31)\end{array}$ & $\begin{array}{c}0.017 * * * \\
(26.63)\end{array}$ & $\begin{array}{c}0.001 * * * \\
(4.81)\end{array}$ & $\begin{array}{c}-0.003 * * * \\
(-13.99)\end{array}$ & $\begin{array}{c}0.0007^{* * * *} \\
(3.72)\end{array}$ & $\begin{array}{c}0.00616 \text { *** } \\
(19.44)\end{array}$ & $\begin{array}{c}0.0123 * * * \\
(23.84)\end{array}$ \\
\hline Year Dummy & Yes & Yes & Yes & Yes & Yes & Yes & Yes & Yes & Yes & Yes & Yes & Yes & Yes & Yes & Yes \\
\hline Obs. & 3228 & 3228 & 3228 & 3228 & 3228 & 1040 & 1040 & 1040 & 1040 & 1040 & 2188 & 2188 & 2188 & 2188 & 2188 \\
\hline \multicolumn{16}{|c|}{ Market Return with Gold Price } \\
\hline & \multicolumn{5}{|c|}{ Full Sample 2001-2018 } & \multicolumn{5}{|c|}{ Split Sample 2001-2007 } & \multicolumn{5}{|c|}{ Split Sample 2008-2018 } \\
\hline & OLS & P25th & P50th & P75th & P90th & OLS & P25th & P50th & P75th & P90th & OLS & P25th & P50th & P75th & P90th \\
\hline Gold Price & $\begin{array}{c}0.00584 \\
(0.29)\end{array}$ & $\begin{array}{c}-0.00641 \\
(-0.24)\end{array}$ & $\begin{array}{l}-0.0100 \\
(-0.51)\end{array}$ & $\begin{array}{c}-0.00399 \\
(-0.13)\end{array}$ & $\begin{array}{l}0.0278 \\
(0.62)\end{array}$ & $\begin{array}{l}0.0326 \\
(0.78)\end{array}$ & $\begin{array}{l}0.0603 \\
(1.02)\end{array}$ & $\begin{array}{c}-0.00712 \\
(-0.14)\end{array}$ & $\begin{array}{c}-0.0235 \\
(-0.41)\end{array}$ & $\begin{array}{l}0.0468 \\
(0.59)\end{array}$ & $\begin{array}{l}-0.0180 \\
(-0.78)\end{array}$ & $\begin{array}{c}-0.0368 * \\
(-1.22)\end{array}$ & $\begin{array}{l}-0.0203 \\
(-0.97)\end{array}$ & $\begin{array}{l}-0.0310 \\
(-0.96)\end{array}$ & $\begin{array}{l}-0.0151 \\
(-0.27)\end{array}$ \\
\hline Constant & $\begin{array}{c}0.001 * * * \\
(8.19)\end{array}$ & $\begin{array}{c}-0.004 * * * \\
(-18.49)\end{array}$ & $\begin{array}{c}0.001 * * * \\
(7.03)\end{array}$ & $\begin{array}{c}0.007^{* * *} \\
(29.38)\end{array}$ & $\begin{array}{c}0.014^{* * *} \\
(37.50)\end{array}$ & $\begin{array}{c}0.002 * * * \\
(5.68)\end{array}$ & $\begin{array}{c}-0.004^{* * * *} \\
(-9.22)\end{array}$ & $\begin{array}{c}0.002 * * * \\
(5.49)\end{array}$ & $\begin{array}{c}0.009 \text { *** } \\
(20.67)\end{array}$ & $\begin{array}{c}0.017 * * * * \\
(26.59)\end{array}$ & $\begin{array}{c}0.001^{* * * *} \\
(5.14)\end{array}$ & $\begin{array}{c}-0.004^{* * * *} \\
(-15.78)\end{array}$ & $\begin{array}{c}0.0006^{* * *} \\
(3.45)\end{array}$ & $\begin{array}{c}0.0064^{* * *} \\
(22.65)\end{array}$ & $\begin{array}{c}0.012^{* * * *} \\
(25.43)\end{array}$ \\
\hline Year Dummy & Yes & Yes & Yes & Yes & Yes & Yes & Yes & Yes & Yes & Yes & Yes' & Yes & Yes & Yes & Yes \\
\hline Obs. & 3228 & 3228 & 3228 & 3228 & 3228 & 1040 & 1040 & 1040 & 1040 & 1040 & 2188 & 2188 & 2188 & 2188 & 2188 \\
\hline
\end{tabular}

Note: $t$ statistics in parentheses ${ }^{*} p<0.05,{ }^{* *} p<0.01{ }^{* * *} p<0.001$. 
Table 6, shows the results of the market return with an exchange rate on a monthly basis. The results of OLS regression show that the exchange rate fluctuations have a negative impact on market return, and the quantile regression also indicates that the exchange rate has a negative impact on market return, except for the last quartile of the sampled period which is significantly negative. In the next phase of the analysis, after splitting the full sample, the same relationship is applied to examine the effect of the exchange rate on market return. The results are quite similar to the overall sample results; however, the magnitudes are different. The first split sample results show an insignificant but negative relation of the exchange rate on market return. Similarly, the second split sample results show the exchange rate has a negative impact on market return, which is in line with the full sample results except for the last quarter. In contrast, the OLS regression results of the market return with the gold price monthly show that the fluctuations in the gold price have a negative impact on market return which is positive in the case of daily observations.

On the other hand, the quantile regression shows the more robust results that the gold price has a negative impact on market return for all quarters of the sampled period. In the next phase of the analysis, after splitting the full sample, the same relationship is applied to examine the effect of the gold price on the market return. The results are quite different from the overall sample results. The first split sample results show a significantly negative relation of gold price on market return in OLS, while in quantile regression, first, two quarters show significantly negative and others show an insignificant negative relationship, respectively. The second split sample shows interesting results, in that the gold price has an insignificant positive impact on market return for both OLS and the first two-quarters of quantile regression while the last two quarters show a negative relation. The direction and significance of the before and after split sample results directly indicate that the fluctuations of the gold price show a diver's effect on market return. Figure 1, presents the graphical exhibitions which correspondingly reveal the depiction of market returns, exchange rate, and gold price fluctuations and the relationship of market return with the exchange rate. 
Table 6. Regression results (Monthly).

\begin{tabular}{|c|c|c|c|c|c|c|c|c|c|c|c|c|c|c|c|}
\hline \multicolumn{16}{|c|}{ Market Return with Exchange Rate } \\
\hline & \multicolumn{5}{|c|}{ Full Sample 2001-2018 } & \multicolumn{5}{|c|}{ Split Sample 2001-2007 } & \multicolumn{5}{|c|}{ Split Sample 2008-2018 } \\
\hline & OLS & P25th & P50th & P75th & P90th & OLS & P25th & P50th & P75th & P90th & OLS & P25th & P50th & P75th & P90th \\
\hline $\begin{array}{l}\text { Exchange } \\
\text { Rate }\end{array}$ & $\begin{array}{l}-1.421 \\
(-1.76)\end{array}$ & $\begin{array}{l}-1.208 \\
(-1.04)\end{array}$ & $\begin{array}{l}-1.193 \\
(-1.49)\end{array}$ & $\begin{array}{l}-1.900 \\
(-1.72)\end{array}$ & $\begin{array}{l}-2.756^{*} \\
(-2.00)\end{array}$ & $\begin{array}{l}-1.604 \\
(-0.75)\end{array}$ & $\begin{array}{l}-0.162 \\
(-0.06)\end{array}$ & $\begin{array}{l}-0.867 \\
(-0.30)\end{array}$ & $\begin{array}{l}-4.279 \\
(-1.24)\end{array}$ & $\begin{array}{l}-6.911 \\
(-1.28)\end{array}$ & $\begin{array}{l}-1.207 \\
(-1.51)\end{array}$ & $\begin{array}{l}-1.631 \\
(-1.27)\end{array}$ & $\begin{array}{l}-0.857 \\
(-1.00)\end{array}$ & $\begin{array}{l}-0.507 \\
(-0.51)\end{array}$ & $\begin{array}{l}-0.933 \\
(-0.68)\end{array}$ \\
\hline Constant & $\begin{array}{c}0.023^{* * * *} \\
(7.27)\end{array}$ & $\begin{array}{l}0.0003 \\
(0.08)\end{array}$ & $\begin{array}{c}0.023^{* * * *} \\
(7.33)\end{array}$ & $\begin{array}{c}0.047^{* * * *} \\
(10.92)\end{array}$ & $\begin{array}{c}0.077^{* * * *} \\
(14.40)\end{array}$ & $\begin{array}{c}0.032 * * * \\
(4.66)\end{array}$ & $\begin{array}{l}-0.000 \\
(-0.04)\end{array}$ & $\begin{array}{c}0.027 * * \\
(2.94)\end{array}$ & $\begin{array}{c}0.070^{* * *} \\
(6.35)\end{array}$ & $\begin{array}{c}0.101 * * * \\
(5.85)\end{array}$ & $\begin{array}{l}0.018^{* * * *} \\
(5.55)\end{array}$ & $\begin{array}{l}-0.0006 \\
(-0.12)\end{array}$ & $\begin{array}{c}0.019 * * * \\
(5.31)\end{array}$ & $\begin{array}{c}0.043^{* * *} \\
(10.31)\end{array}$ & $\begin{array}{c}0.066^{* * *} \\
(11.46)\end{array}$ \\
\hline Year Dummy & Yes & Yes & Yes & Yes & Yes & Yes & Yes & Yes & Yes & Yes & Yes & Yes & Yes & Yes & Yes \\
\hline Obs. & 204 & 204 & 204 & 204 & 204 & 66 & 66 & 66 & 66 & 66 & 138 & 138 & 138 & 138 & 138 \\
\hline \multicolumn{16}{|c|}{ Market Return with Gold Price } \\
\hline & \multicolumn{5}{|c|}{ Full Sample 2001-2018 } & \multicolumn{5}{|c|}{ Split Sample 2001-2007 } & \multicolumn{5}{|c|}{ Split Sample 2008-2018 } \\
\hline & OLS & P25th & P50th & P75th & P90th & OLS & P25th & P50th & P75th & P90th & OLS & P25th & P50th & P75th & P90th \\
\hline Gold Price & $\begin{array}{l}-0.0961 \\
(-0.95)\end{array}$ & $\begin{array}{l}-0.187 \\
(-1.35)\end{array}$ & $\begin{array}{c}-0.0834 \\
(-0.78)\end{array}$ & $\begin{array}{l}-0.188 \\
(-1.45)\end{array}$ & $\begin{array}{l}-0.138 \\
(-0.61)\end{array}$ & $\begin{array}{l}-0.502 * \\
(-2.07)\end{array}$ & $\begin{array}{c}-0.815^{*} \\
(-2.32)\end{array}$ & $\begin{array}{c}-0.554^{*} \\
(-2.04)\end{array}$ & $\begin{array}{l}-0.444 \\
(-1.09)\end{array}$ & $\begin{array}{l}-0.130 \\
(-0.19)\end{array}$ & $\begin{array}{l}0.007 \\
(0.07)\end{array}$ & $\begin{array}{c}-0.0003 \\
(0.00)\end{array}$ & $\begin{array}{c}0.0350 \\
(0.31)\end{array}$ & $\begin{array}{l}-0.0469 \\
(-0.35)\end{array}$ & $\begin{array}{c}-0.0399 \\
(-0.31)\end{array}$ \\
\hline Constant & $\begin{array}{c}0.023 * * * * \\
(7.27)\end{array}$ & $\begin{array}{l}-0.0037 \\
(-0.86)\end{array}$ & $\begin{array}{c}0.023 * * * \\
(7.01)\end{array}$ & $\begin{array}{c}0.049 * * * \\
(12.06)\end{array}$ & $\begin{array}{c}0.074^{* * * *} \\
(10.27)\end{array}$ & $\begin{array}{c}0.034 * * * \\
(5.24)\end{array}$ & $\begin{array}{l}0.004 \\
(0.46)\end{array}$ & $\begin{array}{c}0.033 * * * \\
(4.51)\end{array}$ & $\begin{array}{c}0.067^{* * * *} \\
(5.99)\end{array}$ & $\begin{array}{c}0.104 * * * * \\
(5.65)\end{array}$ & $\begin{array}{c}0.018 * * * \\
(5.45)\end{array}$ & $\begin{array}{c}0.00008 \\
(0.01)\end{array}$ & $\begin{array}{c}0.0205^{* * * *} \\
(5.43)\end{array}$ & $\begin{array}{c}0.0449^{* * * *} \\
(9.95)\end{array}$ & $\begin{array}{c}0.0664 * * * * \\
(15.41)\end{array}$ \\
\hline Year Dummy & Yes & Yes & Yes & Yes & Yes & Yes & Yes & Yes & Yes & Yes & Yes & Yes & Yes & Yes & Yes \\
\hline Obs. & 204 & 204 & 204 & 204 & 204 & 66 & 66 & 66 & 66 & 66 & 138 & 138 & 138 & 138 & 138 \\
\hline
\end{tabular}

Note: $t$ statistics in parentheses ${ }^{*} p<0.05,{ }^{* *} p<0.01,{ }^{* * *} p<0.001$. 


\section{Conclusions}

This study examined the exchange rate and gold price volatility with the stock market returns of an emerging market, "Pakistan", using daily and monthly data from 2001: Q3 to 2018: Q4. For the analysis, this study uses quantile regression to investigate and provide new insights into multiple quantiles, which confirms the empirical results and provides consistent and more precise results in multiple phases. In the first phase, the full sample period is used for the analysis. In the second phase, the sample period is divided into two sub-sample periods based on the U.S. financial crises and structural shifts in the country. The full sample results of this study provide evidence of the negative impact of exchange rate and gold price volatility on the stock market performance. These results are in line and support the argument of previous studies, which confirms that the stock market influenced the exchange rate and commodities (gold) fluctuations and negatively correlated (Tsai 2012; Akkoc and Civcir 2019).

The split sample results are quite different from the overall sample results. The first split sample (2001-2007) results show insignificant but negative relation of exchange rate on market return (daily and monthly). While, in the second split sample (2008-2018), the results show that the exchange rate has a negative and significant impact on the market return (daily) and negatively insignificant (monthly), which is in line with the full sample results except for P90th. In contrast, the first split sample results show mixed relation of the gold price with the market return (daily) and significantly negative (monthly) in the first two quantiles. On the other hand, the second split sample results show that the gold price has an insignificant but negative impact on the market return (daily and monthly) and significantly negative during P25th (Daily). The direction and significance of the split sample results demonstrate that the exchange rate and gold price fluctuations have a more significant effect on the market return in the second split sampled period.

This study examined the exchange rate and gold price relation with market returns considering Pakistan as an emerging market and concluded that the exchange rate and gold price fluctuations have negative impact on market returns. The inclusion of gold as a commodity in this study is due to the preferred cultural habitat of a lot of retail investors in Southeast Asian countries, including Pakistan, and it also has greater liquidity compared to other investment assets. Further studies may consider other commodities, including oil and currency pairs, to re-examine the same relationship, and could find more robust results to control the balanced portfolio effect. Our results have significant implications for both professional investors and policymakers to develop a useful and practical policy to smoothing the volatilities from commodities to domestic variables. The political unrest, trade deficit, and adoption of the IMF's back-to-back packages rapidly raised the exchange rates. Government officials-built bailout packages to overcome economic distress, including Rs. Twenty billion was announced in May 2019 and lay with the security and exchange commission of Pakistan (SECP) to protect investors, ensuring that the market is efficient, transparent, and reduces systematic risk.

Author Contributions: Conceptualization, data curation, methodology, software and formal analysis, and preparation of original and revised draft, R.A.; reviewed the revised draft as Supervisory role, I.U.M.; conceptualization, software and formal analysis, Reviewed the revised draft, R.U.R.; resource support, investigation and validation, W.X., M.A.N., and M.I.A. Lastly, thanks to anonymous reviewers whose useful suggestions added significant value in the document. All authors have read and agreed to the published version of the manuscript.

Funding: There is no external funding of this research.

Conflicts of Interest: The authors declare no conflict of interest.

\section{References}

Akkoc, Ugur, and Irfan Civcir. 2019. Dynamic linkages between strategic commodities and stock market in Turkey: Evidence from SVAR-DCC-GARCH model. Resource Policy 62: 231-39. [CrossRef]

Arouri, Mohamed El Hedi, Amine Lahiani, and Duc Khuong Nguyen. 2015. World gold prices and stock returns in China: Insights for hedging and diversification strategies. Economic Modelling 44: 273-82. [CrossRef] 
Aye, Goodness C., Hector Carcel, Luis A. Gil-Alana, and Rangan Gupta. 2017. Does gold act as a hedge against inflation in the UK? Evidence from a fractional cointegration approach over 1257 to 2016. Resources Policy 54: 53-57. [CrossRef]

Bampinas, Georgios, and Theodore Panagiotidis. 2015. Are gold and silver a hedge against inflation? A two-century perspective. International Review of Financial Analysis 41: 267-76. [CrossRef]

Baur, Dirk G. 2012. Asymmetric Volatility in the Gold Market. Journal of Alternative Investments 14: 26-38. [CrossRef]

Baur, Dirk G., and Brian M. Lucey. 2010. Is gold a hedge or a safe haven? An analysis of stocks, bonds and gold. Financial Review 45: 217-29. [CrossRef]

Baur, Dirk G., and Thomas K. McDermott. 2010. Is gold a safe haven? International evidence. Journal of Banking Finance 34: 1886-98. [CrossRef]

Beckmann, Joscha, Theo Berger, and Robert Czudaj. 2015. Does gold act as a hedge or a safe haven for stocks? A smooth transition approach. Economic Modelling 48: 16-24. [CrossRef]

Bouri, E., A. Jain, P. C. Biswal, and D. Roubaud. 2017. Cointegration and nonlinear causality amongst gold, oil, and the Indian stock market: Evidence from implied volatility indices. Resources Policy 52: 201-6. [CrossRef]

Caporale, Guglielmo Maria, John Hunter, and Faek Menla Ali. 2014. On the linkages between stock prices and exchange rates: Evidence from the banking crisis of 2007-2010. International Review of Financial Analysis 33: 87-103. [CrossRef]

CEIC Data. 2020. Available online: https://www.ceicdata.com/en (accessed on 11 May 2020).

Chen, An-Sing, and James Wuh Lin. 2014. The relation between gold and stocks: An analysis of severe bear markets. Applied Economics Letters 21: 158-70. [CrossRef]

Delgado, Nancy Areli Bermudez, Estefanía Bermudez Delgado, and Eduardo Saucedo. 2018. The relationship between oil prices, the stock market and the exchange rate: Evidence from Mexico. The North American Journal Economics Finance 45: 266-75. [CrossRef]

Dickey, David A., and Wayne A. Fuller. 1979. Distribution of the Estimators for Autoregressive Time Series with a Unit Root. Journal of the American Statistical Association 74: 427-31.

Dickey, David A., and Wayne A. Fuller. 1981. Likelihood Ratio Statistics for Autoregressive Time Series with a Unit Root. Econometrica 49: 1057-72. [CrossRef]

Dornbusch, Rudiger, and Stanley Fischer. 1980. Exchange rates and the current account. American Economic Review 70: 960-71.

Ebrahim, Zoheir, Oliver R. Inderwildi, and David A. King. 2014. Macroeconomic impacts of oil price volatility: Mitigation and resilience. Front Energy 8: 9-24. [CrossRef]

Ewing, Bradley T., and Farooq Malik. 2016. Volatility spillovers between oil prices and the stock market under structural breaks. Global Finance Journal 29: 12-23. [CrossRef]

Gokmenoglu, Korhan K., and Negar Fazlollahi. 2015. The interactions among gold, oil, and stock market: Evidence from S\&P500. Procedia Economics and Finance 25: 478-88.

Iqbal, Javed. 2017. Does gold hedge stock market, inflation and exchange rate risks? An econometric investigation. International Review of Economics \& Finance 48: 1-17.

Jain, Anshul, and P. C. Biswal. 2016. Dynamic linkages among oil price, gold price, exchange rate, and stock market in India. Resources Policy 49: 179-85. [CrossRef]

Kanjilal, Kakali, and Sajal Ghosh. 2014. Income and price elasticity of gold import demand in India: Empirical evidence from threshold and ARDL bounds test cointegration. Resources Policy 41: 135-42. [CrossRef]

Kumar, Satish. 2017. On the nonlinear relation between crude oil and gold. Resources Policy 51: 219-24. [CrossRef]

Le, Thai-Ha, and Youngho Chang. 2016. Dynamics between strategic commodities and financial variables: Evidence from Japan. Resources Policy 50: 1-9. [CrossRef]

Leung, Henry, Dirk Schiereck, and Florian Schroeder. 2017. Volatility spillovers and determinants of contagion: Exchange rate and equity markets during crisis. Economic Modelling 61: 169-80. [CrossRef]

Masih, Rumi, Sanjay Peters, and Lurion De Mello. 2011. Oil price volatility and stock price fluctuations in an emerging market: Evidence from South Korea. Energy Economics 33: 975-86. [CrossRef]

Mensi, W., M. Beljid, A. Boubaker, and S. Managi. 2013. Correlations and volatility spillovers across commodity and stock markets: Linking energies, food, and gold. Economic Modelling 32: 15-22. [CrossRef]

Mun, Kyung-Chun. 2007. Volatility and correlation in international stock markets and the role of exchange rate fluctuations. Journal of International Financial Markets Institutions and Money 17: 25-41. [CrossRef] 
Ng, Serena, and Pieere Perron. 2001. Lag Length Selection and the Construction of Unit Root Tests with Good Size and Power. Econometrica 69: 1519-54. [CrossRef]

Pesaran, M. Hashem. 2015. Time Series and Panel Data Econometrics. Oxford: Oxford University Press.

Phillips, Peter CB, and Pierre Perron. 1988. Testing for a unit root in a time series regression. Biometrika 75: 335-46. [CrossRef]

Raza, Naveed, Syed Jawad Hussain Shahzad, Aviral Kumar Tiwari, and Muhammad Shahbaz. 2016. Asymmetric impact of gold, oil prices and their volatilities on stock prices of emerging markets. Resources Policy 49: 290-91. [CrossRef]

Reboredo, Juan C. 2013. Is gold a hedge or safe haven against oil price movements? Resources Policy 38: 130-37. [CrossRef]

Rjoub, Husam, Irfan Civcir, and Nil Gunsel Resatoglu. 2017. Micro and macroeconomic determinants of stock prices: The case of Turkish banking sector. Romanian Journal of Economic Forecasting 20: 150-66.

Schwert, G. William. 2002. Tests for unit roots: A Monte Carlo investigation. Journal of Business E Economic Statistics 20: 5-17.

Sadorsky, Perry. 2014. Modeling volatility and correlations between emerging market stock prices and the prices of copper, oil and wheat. Energy Economics 43: 72-81. [CrossRef]

Shahbaz, Muhammad, Mohammad Iqbal Tahir, Imran Ali, and Ijaz Ur Rehmand. 2014. Is gold investment a hedge against inflation in Pakistan? A co-integration and causality analysis in the presence of structural breaks. The North American Journal of Economics and Finance 28: 190-05. [CrossRef]

Singhal, Shelly, and Sajal Ghosh. 2016. Returns and volatility linkages between international crude oil price, metal and other stock indices in India: Evidence from VAR-DCC-GARCH models. Resources Policy 50: 276-88. [CrossRef]

Sreekanth, D., and L. Krishna Veni. 2014. Causal relationship between gold price and nifty-an empirical study in Indian context. Asian Journal of Research in Banking and Finance 4: 253-65.

Tsai, I-Chun. 2012. The relationship between stock price index and exchange rate in Asian markets: A quantile regression approach. Journal of International Financial Markets Institutions and Money 22: 609-21. [CrossRef]

Tule, Moses Kpughur, Mela Yila Dogo, and Godfrey Chidozie Uzonwanne. 2018. Volatility of stock market returns and the Naira exchange rate. Global Finance Journal 35: 97-105. [CrossRef]

Walid, Chkili, Aloui Chaker, Omar Masood, and John Fry. 2011. Stock market volatility and exchange rates in emerging countries: A Markov-state switching approach. Emerging Markets Review 12: 272-92. [CrossRef]

Wong, Hock Tsen. 2019. Volatility spillovers between real exchange rate returns and real stock price returns in Malaysia. International Journal of Finance E Economics 24: 131-49. 